\title{
VERSITA
}

\section{VISUAL EXPOSURE WITHIN THE DOLNI MORAVA BIOSPHERE RESERVE}

\author{
HANA KUCHYŇKOVÁ ${ }^{1}$, TOMÁŠ MIKITA
}

${ }^{1}$ Mendel University of Agriculture and Forestry, Department of Landscape Architecture, Faculty of Horticulture, Valticka 337, 69144 Lednice, Czech Republic. Tel.: +420 519367 302, E-mail: kuchynkova.hana@centrum.cz

${ }^{2}$ Mendel University of Agriculture and Forestry, Department of Geoinformatics, Faculty of Forestry and Wood Technology, Zemedelska 3, 61300 Brno, Czech Republic. Tel.: +420545134021,E-mail: tomas@mikita.cz

Received: $26^{\text {th }}$ September 2008, Accepted: $20^{\text {th }}$ December 2008

\section{Abstract}

Impacts on landscape character and tools for the support of decision making in the Czech Republic have always been important subjects in the sphere of landscape character and visual/environmental assessment. Only one publication could be found, however, that dealt with the use of landscape indicators for evaluating landscape character in the Czech Republic. In this study, we add to this by addressing the issue of visual exposure.

In this project, we construct and compare two possible alternatives for computing visual exposure using GIS tools. The two alternatives differ in using a regular grid layer of viewpoints or of viewpoints based on actual use of frequented sites. The procedure was verified using the model area of the Dolni Morava Biosphere Reserve. The version based on most frequented sites produced a map with increased areas of visual exposure. This paper also goes on to suggest changes to the present regulations and other practical applications of the method.

Keywords: Visibility, GIS, ArcGIS Desktop, Landscape character, Czech Republic

\section{INTRODUCTION}

Both impacts on the character of landscapes and tools for supporting decision making in the Czech Republic have long been important subjects within the sphere of landscape character and visual/environmental assessment. Little literature exists on the subject in the Czech Republic, however, and the authors could find only one paper that dealt with the use of landscape indicators for evaluation of landscape character (Lipsky and Romportl 2006). In this study, we add to this by addressing the issue of visual exposure.

The visual exposure of a landscape is a landscape characteristic that expresses its degree of resistance to change (e.g. development, changes in land use). There is a crucial difference, however, between an area that is visible and an area that is visually exposed, the main difference being determined by the human factor. The method for evaluating visual exposure within a landscape is based on assessing the impact of a proposed project on the character of that landscape. Today, geographical information system (GIS) tools are 
commonly used to calculate visual exposure, especially in case studies for wind power plants and antenna masts. Assessments of visual exposure can be used for preventive evaluations. Preventive evaluations usually define a set of precautions that help to prevent irreparable damage to the environment in advance of a project, as opposed to the process of causal evaluation, in which possible impacts on the environment are assessed at the same time as a project is undertaken.

We generally understand visual exposure to refer to that part of the landscape that is exposed to the perception of most observers. Visually exposed areas that also happen to be of particular scenic, historic or aesthetic value are especially vulnerable to changes in landscape character. A respect for the sensibility of the landscape and an understanding of its vulnerability is a core condition for the sustainable development of an area.

In this paper, we describe a new method for assessing visual exposure that will contribute to the protection of those characteristics that contribute to the scenic, historic or aesthetic quality of the landscape.

This paper assesses whether the use of observation points (actual viewpoints used by people) or points chosen at random (some of which may be totally inaccessible to people) are best suited to calculating visual exposure in a case study area. The methods were tested in the Dolni Morava Biosphere Reserve in South Moravia (Figure 1). Any improvement in the method for assessing visual exposure will contribute to the protection of those characteristics that contribute to the scenic, historic or aesthetic quality of the landscape. It will also help prevent factors that impact on the landscape, in accordance with $\S 12$ of Act No. 114/1992 Coll. on the Protection of Nature and the Landscape, included in part 2 of the General Protection of Nature Act. As part of this project, therefore, we also suggest draft changes to regulations within the Biosphere Reserve.

Fig. 1: Location of the Dolni Morava Biosphere Reserve in the Czech Republic.

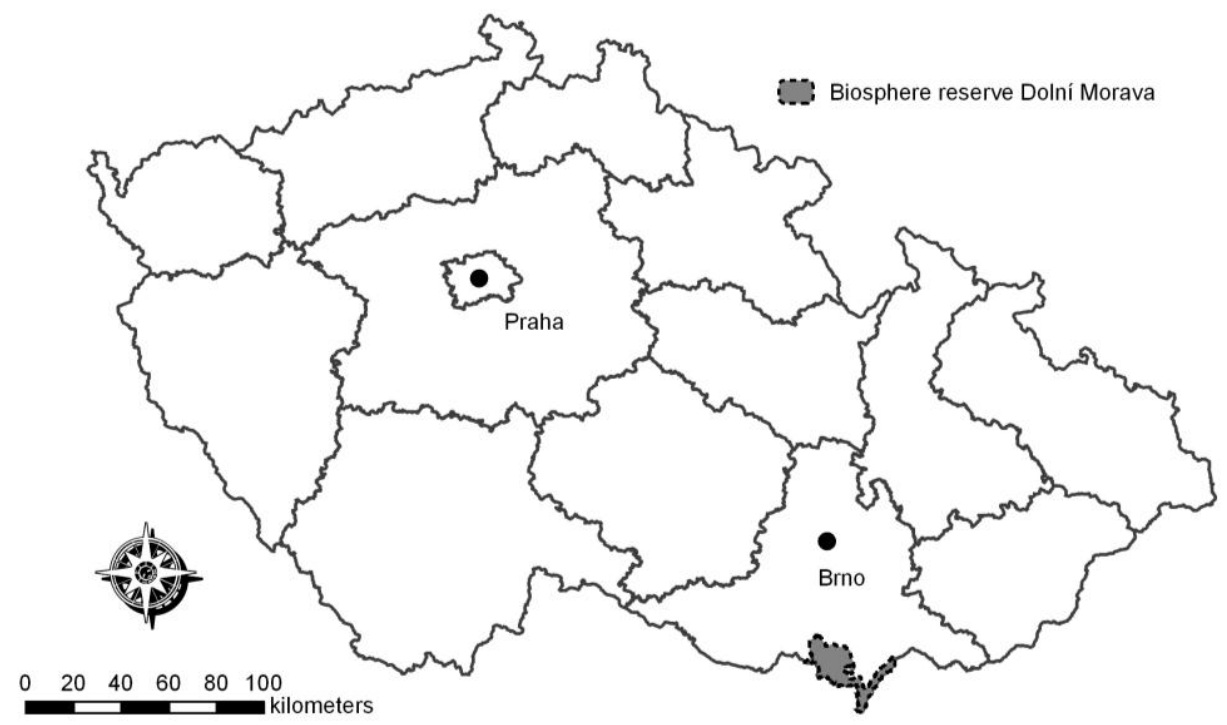

\section{Visibility versus visual exposure}

We speak of a visible landscape in relation to the area that can be seen from a particular site or the location of a project. Analyses of visibility based on viewshed are among the 
most frequently used analytical tools in GIS (Ramos and Panagopoulos 2004), are unique according to Rana and Morley (2002), and continue to find new practical applications in a wide variety of fields, and particularly within the visual impact assessment process (Leitao 1997; O'Sullivan and Turner 2001). The GIS tools create a Boolean pattern that classifies all the pixels into those visible from a given point (value 1) and those not visible (value 0). Its output is usually a two-dimensional map of all areas visible from a given point at a given height (Hanna 2003). A simplified principle of viewshed analysis, a tool commonly used in GIS, is shown in Figures 2 and 3. In this way, it is possible to determine visibility from a single point for wide regions (Kent 1986; Howes and Gattrell 1993). Simulation of visibility is also a crucial tool in the fields of urbanisation, landscape planning, landscape character assessment and environmental impact assessment (Canter 1995; The Landscape Institute and Institute of Environmental Management and Assessment 2002).

Fig. 2: Principle of determination of visible areas (source: Klimanek 2006).

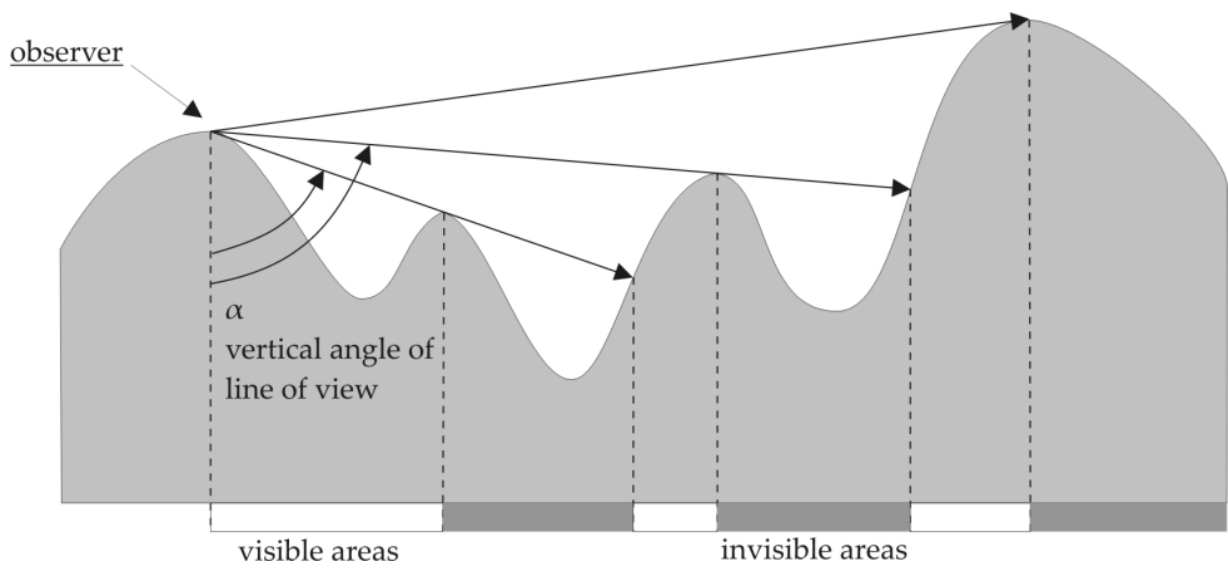

Fig. 3: Principle of using the Viewshed tool in ArcGIS 9.2. (source: ESRI 2002).

\section{Controlling visibility in a viewshed}

- Set parameters as observer point attributes

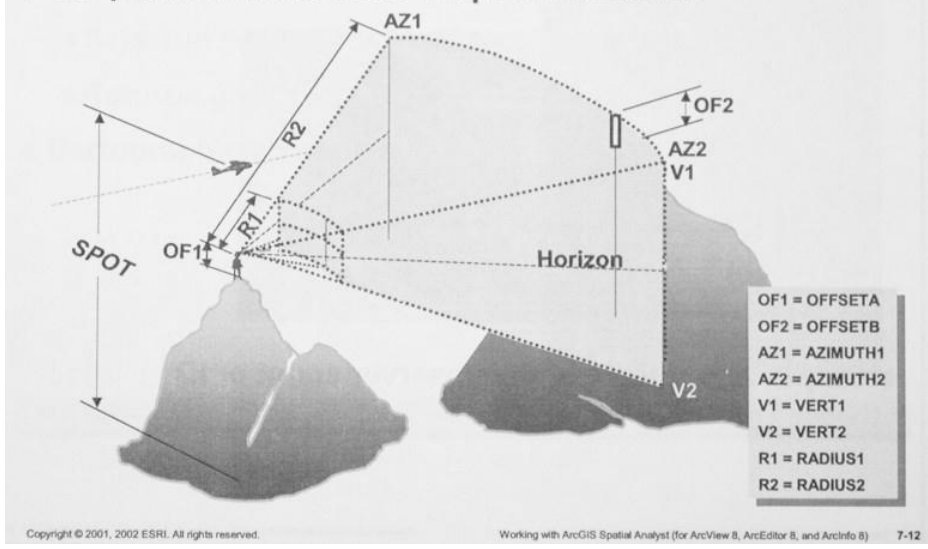


A visually exposed landscape relates to that part of the landscape that is exposed to the perception of many observers. Visual exposure is especially influenced by how frequently the area is visited, as well as by the openness of landscape scenery, illumination and land relief (Salasova et al. 2008). When speaking of visually exposed places, we mean not only places that can be seen, or are seen, from one location but also those seen from a great number of observation points. Changes in landscape character in visually exposed places, therefore, have a large impact on a great number of inhabitants and visitors, including those in other parts of the landscape from where those places are visible. Salasova et al. (2007) note that visually exposed areas with high natural, cultural, historical and/or aesthetic value are, in terms of landscape character protection, vulnerable and have little resistance to change. In this context, it is essential to study the effect of changes on visual exposure rather than on visibility.

\section{Evaluation of visual exposure}

Visual exposure can be evaluated in several ways. One is the evaluation of visual exposure through panoramas (Jancura et al. 2001). A second is evaluation using a digital elevation model (DEM). This project focuses on the latter. The use of DEMs and GIS functionality allows both local and large-scale evaluation of visibility within landscapes (GIS enables one to evaluate visibility using a huge number of entry observer points). The assessment of visual impact improves in proportion to the number of entry points entered, i.e. the number of pixels in the resulting pattern range from 0 to $\infty$, depending on the number of points from which they can be seen and the visual impact from individual places. We use the term intervisibility for this type of analysis (Mills et al. 1992; Rana and Morley 2002; Möller 2007). With intervisibility, however, the observation points are not determined in advance, and points representing cell centroids are used instead. The analysis of intervisibility thus counts the visibility from each cell of the input raster in the DEM of land relief for each cell (Möller 2007). It follows from this that the resolution of the input DEM is crucial for the accuracy of the calculation and time required for making the calculation.

The aim of this paper is to compare the outputs of visual exposure analysis for the Dolni Morava Biosphere Reserve, Czech Republic (Figure 1), calculated using two different sets of observation points. In the first case, the input group comprises more or less random points generated by a computer in a regular raster pattern of $500 \times 500 \mathrm{~m}$. In this case, the points of the grid are not likely to truly reflect the actual or most likely used viewpoints of observers, tourists or inhabitants in the area of interest. In the second case, we proceed from the assumption that the visual exposure of an area is also influenced by frequency of occurrence of observers over time. The input points of the second analysis mostly represent routes and points most frequented by people (such as roads and paths, walking and cycling trails and viewpoints).

\section{MATERIALS AND METHODS}

ArcGIS Desktop 9.2 software (including Spatial Analyst, 3D Analyst and Hawth's Tools extensions) was used for processing the input data layers.

GIS visibility tools identify pixels from the input DEM visible from one or more observation points or lines placed at specific elevations within the DEM (ESRI 2002). These points or lines represent those places frequently visited by large numbers of people. Each pixel of the output raster receives a value equivalent to the number of points from 
which the given pixel is visible. If there is only one point, i.e. the viewpoint of the observer, then each pixel visible from this point receives a value of 1 . All other pixels that cannot be seen from the viewpoint of the observer receive a value of 0. Using ArcGIS, many parameters of visibility analysis can be adjusted, including the height of the observer, height of the observed object, and radius of the visible area. For our purposes, only the OFFSETA parameter was set, i.e. the height of the observer $(160 \mathrm{~cm})$. Although the input features can be either points or lines, only input point features were used in this analysis. Data needed for this type of analysis comprises a set of observation points and a DEM representing the relief of the area of interest, land cover data, and information on the height of vertical objects such as buildings, trees and forests stands. The inclusion of such objects, in the form of polygonal, linear or point features, allows the DEM to be adapted such that it better corresponds with reality (Kent 1986; Miller et al. 1994).

\section{Digital model of the terrain}

A digital model of the terrain of the Dolni Morava Biosphere Reserve was created in raster format using the TopoToRaster module, an extension to the Spatial Analyst software of ArcGIS 9.2. The fundamental base of geographic data (ZABAGED), in the form of contour lines with an interval of $5 \mathrm{~m}$, was used as the basic input, which was then further supplemented with apexes. From this input, a DEM of the Dolni Morava Biosphere Reserve was created with a $5 \times 5 \mathrm{~m}$ pixel size and including a $5 \mathrm{~km}$ wide buffer zone on the Czech side of the border.

\section{Visual barriers}

Data on the height of certain features in the landscape, such as areas of forest, linear vegetation, solitary trees and buildings, were added to the DEM in order to provide a truer approximation of visual barriers within the landscape. In the case of forests, information on the height of trees was obtained from data within the appropriate forestry management plan. For other vertical objects, such as buildings or linear vegetation, no complex database exists that includes height. An average height of $7 \mathrm{~m}$ was assigned to all buildings, therefore, and an average width or crown diameter for linear vegetation and solitary trees. For linear vegetation, we assigned an average width of $10 \mathrm{~m}$ and a height of $15 \mathrm{~m}$, and for solitary trees (solitary trees in the alluvial plain tend to be larger) we assigned a crown diameter of $15 \mathrm{~m}$ and height of $20 \mathrm{~m}$.

\section{Analysis of visibility 1}

For the first method, a regular 500 x $500 \mathrm{~m}$ grid of "possible observation points" was generated for the DEM. Hawth's Tools (downloaded free as an extension to ArcGIS software from www.spatialecology.com) were used to create the grid of points as the Spatial Analyst software of ArcGIS 9.2 does not include tools for generating such regular or irregular grids. These input points represent the whole area of interest in reduced resolution. While it would be optimal to use a resolution of $1 \times 1 \mathrm{~m}$, the resulting output of observer points would be too dense to be visible on a standard computer screen. Data for the heights of possible visual barriers, such as buildings, forest growth, linear vegetation and solitary trees, were then overlaid. In total, there were 2,153 observation points, including the $5 \mathrm{~km}$ buffer zone from the boundary of the Biosphere Reserve (Figure 4).

When applying the Viewshed tool to the basic data (grid and enhanced DEM), each pixel receives a value equal to the number of points (from the input point layer) from which it is 
visible. After reclassifying the results into five categories (Table 1) based upon their natural breaks $^{1}$, the values were used to create a plan of visual exposure for the Biosphere Reserve.

Fig. 4: Input data for the digital relief model, including vertical objects and the net of observation points for version 1 of the analysis.

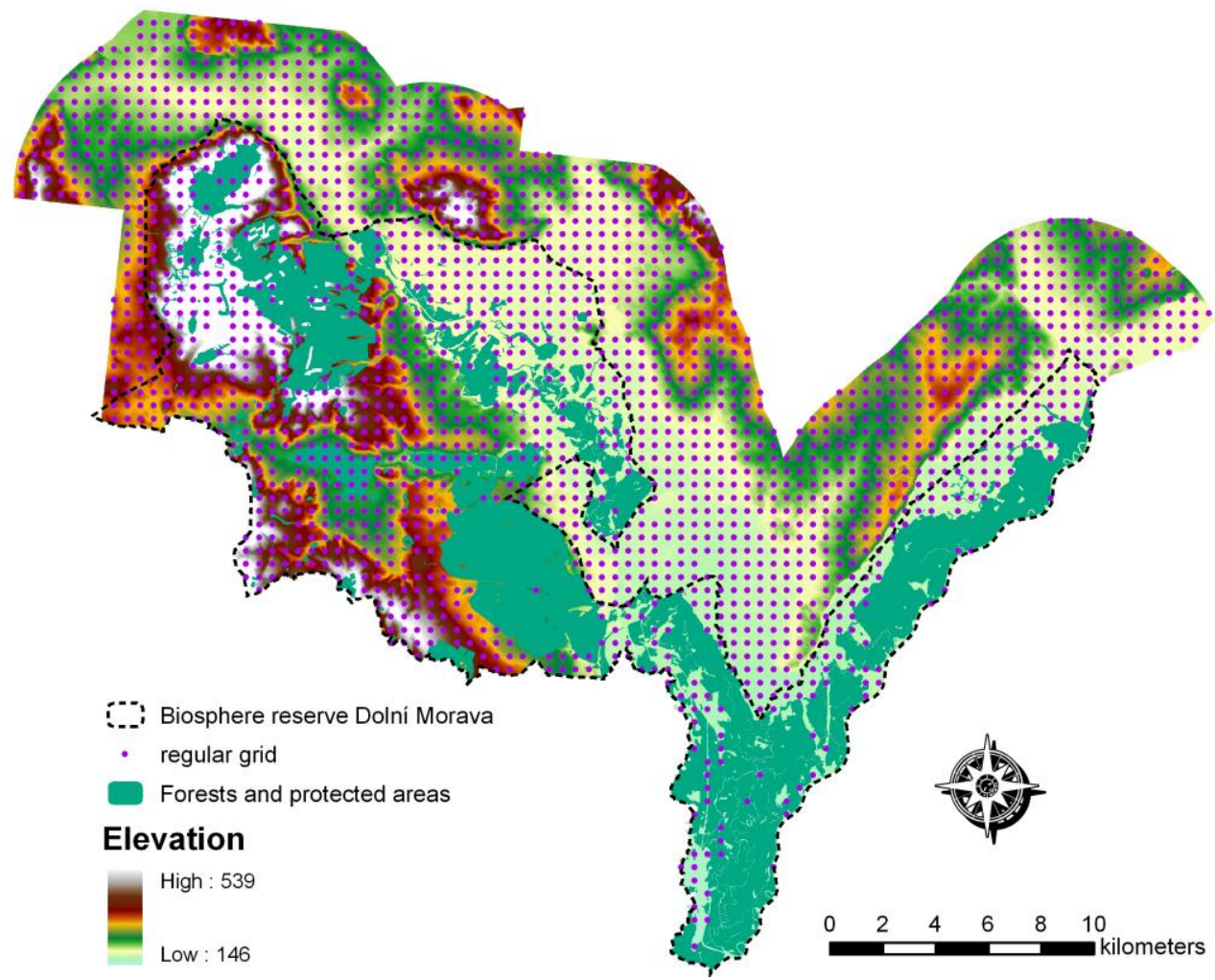

\section{Analysis of visibility 2}

In the first analysis, viewpoints were spread evenly over the area of interest. In a real landscape, however, the movement of people tends to concentrate along roads, footpaths or close to villages and towns - people tend not to stray into fields often.

The second analysis of visual exposure, therefore, focussed on sites where a higher concentration of movement could be expected, such as roads used by vehicles, forest roads and paths, walking and cycling trails, viewpoints, riverbanks, urban areas, gardens, orchards, or cemeteries. Data for these layers were again taken from ZABAGED. The layer for walking trails was created through digitalization of a map for hikers, changing the coordinate system from S-42 into S-JTSK. A buffer layer was created for each data layer that took into account possible movement of the observer into the surrounding area of the

\footnotetext{
${ }^{1}$ Natural breaks are a classification system recommended for continuous data (Mitchell 1999). GIS automatically determines the high and low values for each class, using a mathematical procedure to test different class breaks. It picks the class breaks that best group similar values and maximise the differences between classes.
} 
trail. The width of these buffers was assessed based upon the character of the data layer, i.e. roads and motorways $-20 \mathrm{~m}$, walking trails $-10 \mathrm{~m}$ and urban areas $-100 \mathrm{~m}$. A polygon layer was created by compiling all data layers and their buffer areas with the help of the Random Points tool (an extension of Hawth's Tools). A total of 5,000 observation points, with a minimal inter-point distance of $100 \mathrm{~m}$, were added to the DEM (Figure 5). As for version 1, the Viewshed tool was used to analyse the basic data (grid and enhanced DEM), with each pixel receiving a value equal to the number of points (from the input point layer) from which it is visible. After reclassifying the results into five categories (Table 1) based upon their natural breaks, the values were used to create a plan of visual exposure for the Biosphere Reserve.

Fig. 5: Input data for the digital relief model, including vertical objects and the network of observation points for version 2 of the analysis.

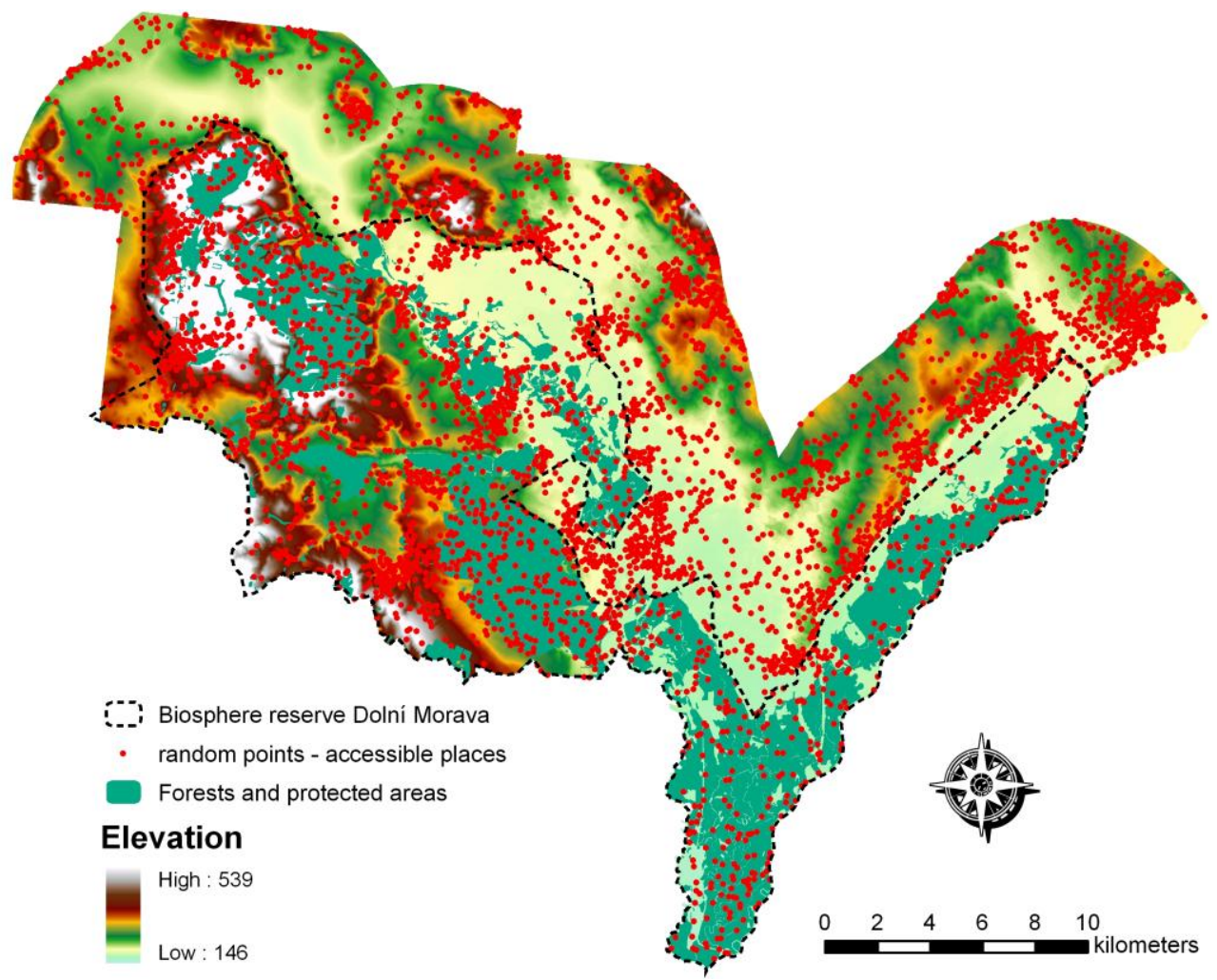

\section{RESULTS AND DISCUSSION}

A comparison of the two raster views created for the Biosphere Reserve indicates clear differences in visual exposure resulting from the choice of input points (Figure 6). A comparison of the percentage representation in individual categories (Table 1) clearly shows that, when using frequented and freely accessible places as observation points (version 2), the range of values with increased visual exposure is much higher. The largest differences are seen particularly in urban areas (Figure 7) and in the area around the 
junction of the Dyje and Morava rivers, which is visible over large distances due to the flat terrain.

Of the two alternatives, therefore, the calculation of version 1, based upon actual viewpoints, led to increased categories of higher visual exposure. In addition, due to the inclusion of actual landscape structures, version 2 also better reflected the actual landscape structure. The calculation methods used in version 2, therefore, can be said to better represent the "actual" visual exposure in the landscape than version 1.

Table 1: Range of values and proportional representation of visual exposure applied within the Dolni Morava Biosphere Reserve using two alternative versions of visual exposure calculation (category 1 represents very low exposure and category 5 represents very high exposure).

\section{Version 1}

\begin{tabular}{c|cc}
\hline Category of visual exposure & Range of values & Proportional representation (\%) \\
\hline 1 & $0-26$ & 74 \\
2 & $27-83$ & 17 \\
3 & $84-183$ & 6 \\
4 & $184-372$ & 2 \\
5 & $373-1,044$ & 1 \\
Version 2 & & \\
\hline Category of visual exposure & Range of values & Proportional representation (\%) \\
\hline 1 & $0-52$ & 50 \\
2 & $53-145$ & 17 \\
3 & $146-312$ & 8 \\
4 & $313-637$ & 13 \\
5 & $638-1,643$ &
\end{tabular}

Assessing the visual exposure of an area is a useful preventive measure, not only for the purposes of evaluating potential impacts on landscape character but also for planning communication facilities, utility lines and supply mains (e.g. TV and GSM aerials, low- and high-voltage lines and wind power plants [Hadrian et al. 1988]) and defence facilities (air corridors and radar bases), as well as for environmental modelling and other landscape projects such as diagrams of visibility (Vorel et al. 2006 ). According to Hanna (2003), however, and as seen from our results above, DEMs calculated without visual barriers only partly resemble reality. We must expect mistakes, therefore, due to inaccuracies and deviations in maps that are too generalised. Other factors that would improve the accuracy of maps of visual exposure include air quality, other visual barriers not included in this project and properties of the observer (properties of human eye, short-sightedness, longsightedness). Further, important factors not incorporated in this analysis were the seasonal and overall dynamics of the landscape. With respect to human activities in the countryside in particular, even small-scale interference may lead to radical changes. Natural processes may also affect visual exposure over time, e.g. through forest growth and reforestation of grassland. In general, it is true that the actual state found through field observations is more accurate than that generated on a computer; however, it is not always feasible to apply this in large areas such as biosphere reserves, protected nature reserves or whole regions. 
Fig. 6: Maps of visual exposure based on an evenly spread grid of observation points (version 1) and based on accessible places (version 2).

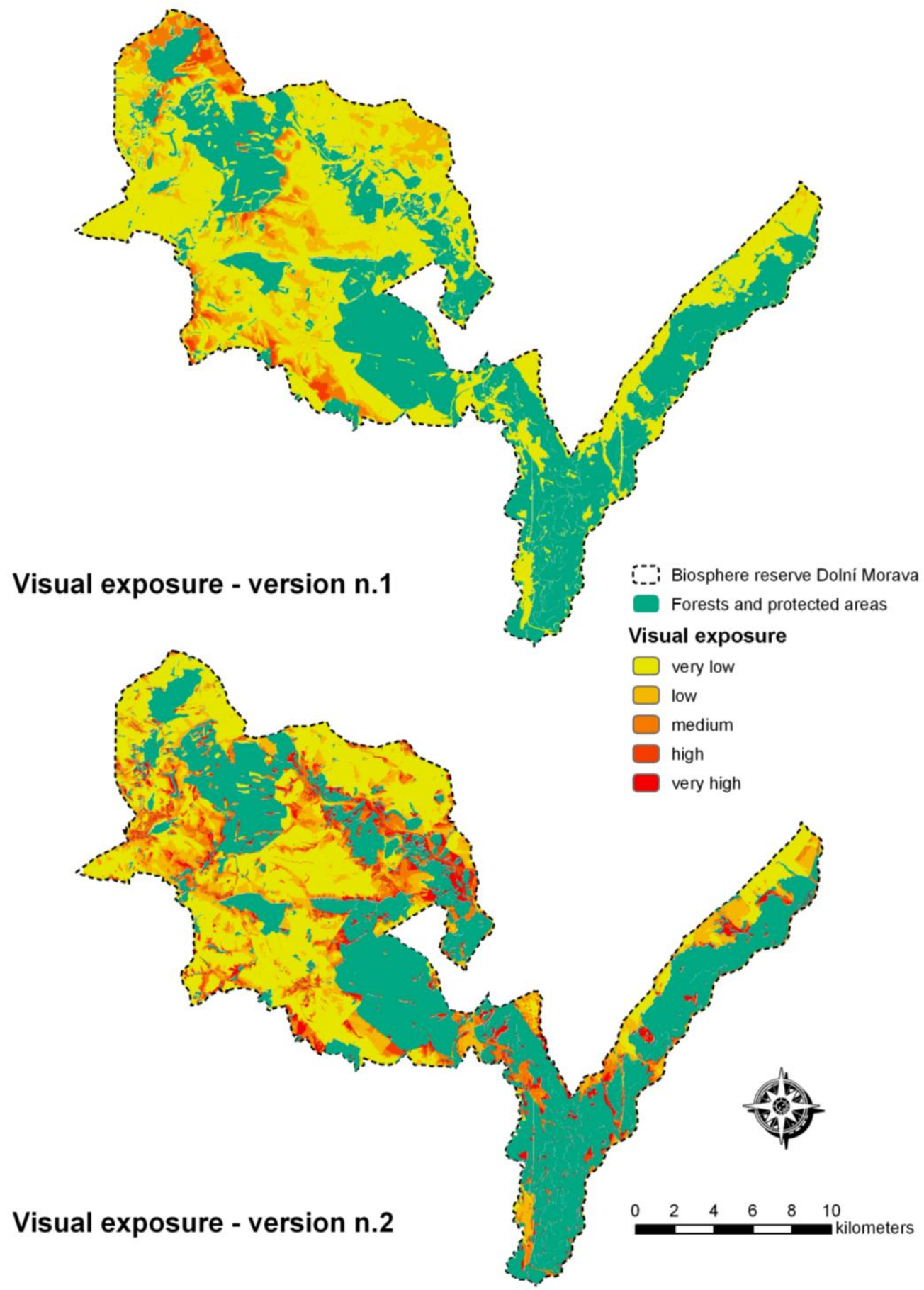


Fig. 7: A detailed comparison of visual exposure based on versions 1 and 2.
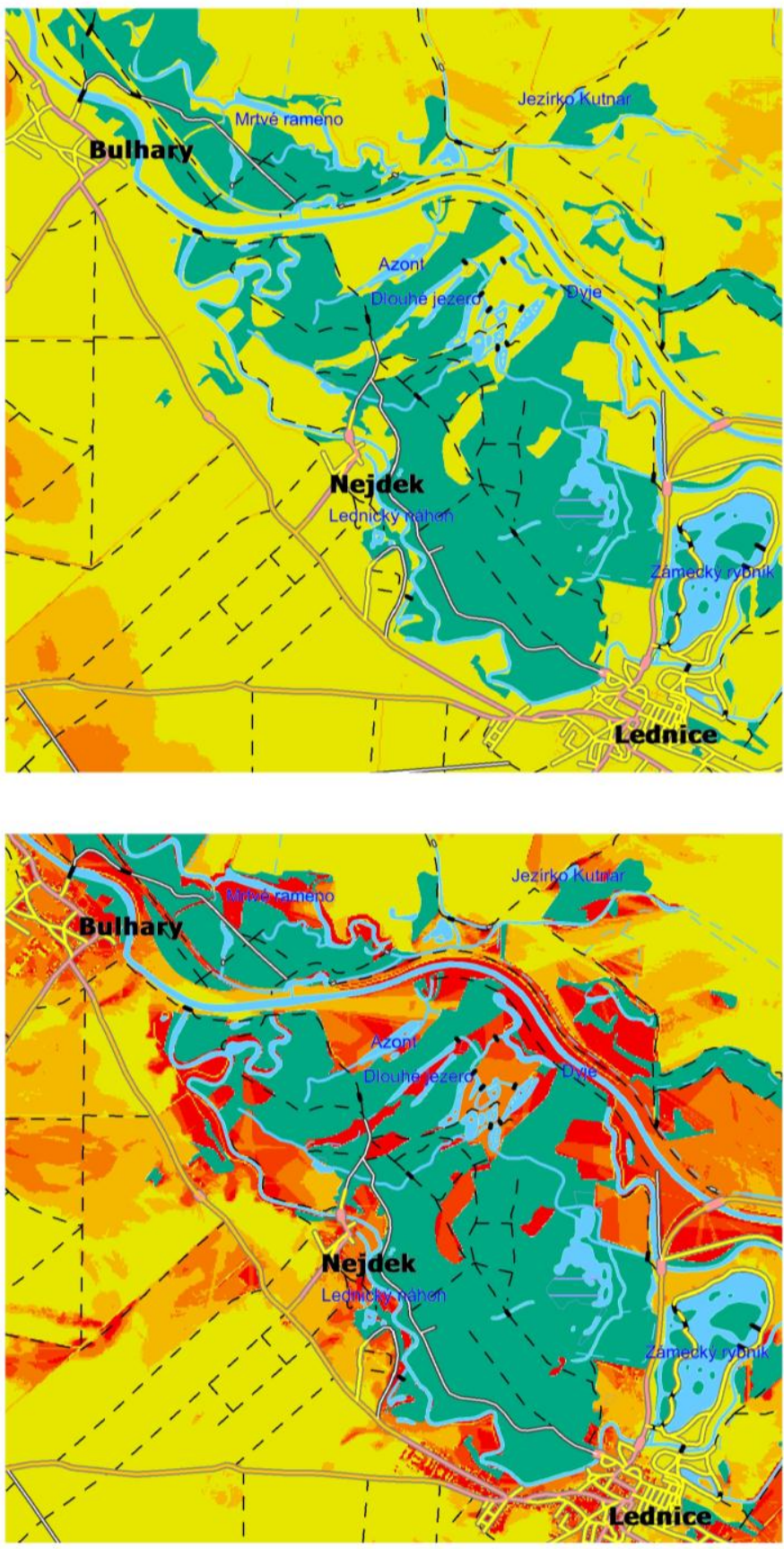

\section{Visual exposure} detail - version n.1

Biosphere reserve Dolní Morava Forests and protected areas

\section{Visual exposure}
$\square$ very low
$\square$ low
$\square$ medium
high
very high

\section{Visual exposure} detail - version n.2 


\section{Practical applications}

Visual exposure analysis, when undertaken from one or a few specific places or sites can be used for causal evaluation of the influence of a project on landscape character. This data can also provide important groundwork for other projects, and especially for preventive landscape character assessment. Visual exposure analysis can also serve as an auxiliary tool for differentiating an area as regards openness of landscape scenery or in finding the visual horizon. A map layer of visual exposure will often overlap with other thematic layers, which can help identify correlations between individual differential factors. It is also possible to restrict the analysis of visual exposure to specific areas by omitting forest growth and small-scale areas, and especially protected areas, where no large-scale interference or changes are expected.

As one of the aims of this project was to help draft new regulations for the Dolni Morava Biosphere Reserve, we have provided a recommended alteration (Box 1) to the present biosphere reserve regulations that takes into account the results of this and previous mapping exercises (e.g. Salasova et al. 2007)

\section{Box 1. Example of a draft regulation, with justification and other recommendations.}

Draft regulation
In areas of higher visual exposure (values $3-5$ ), it is neither appropriate to place buildings,
constructions and other technical facilities nor to carry out significant changes in the use of the
landscape, such as the construction of ski lifts and ski slopes, clearance of forests).
Justification and other recommendations
Changes in landscape character, and especially changes to its basic properties, are most pronounced
in visually exposed areas. These are those areas that are most observed by the public, as they form
integral parts of people's living and holiday spaces. The placing of structures of a technical character
and other large-scale landscape use changes are unsuitable in a landscape of historic, scenic or
aesthetic value, where the risk of negative impact is much higher. In such cases, the intention must
be disallowed.

\section{CONCLUSION}

Both of the alternative versions for calculating visual exposure may be used, but for different purposes. Version 1 is better than version 2 for evaluating visual exposure in the case of preventive landscape character assessment. Version 2, however, is more appropriate for the evaluation of visual exposure in the case of causal landscape character assessment, i.e. for comparing the extent of impact both before and after implementation of a project.

Analysis of visual exposure within preventive landscape character assessment may also function as a supportive tool for differentiating the scenic character of a landscape (e.g. openness or closedness) and to identify visual horizons. In the case of causal landscape character assessment, visual exposure allows a preliminary estimation of the extent of the proposed project's impact (scoping). It should be noted that placing projects or changing land uses at sites with the highest visual exposures do not necessarily mean that landscape character will be impacted, although further research is needed to verify this. 


\section{ACKNOWLEDGEMENTS}

This article was produced as part of project MSMT CR 2B06101 of the Ministry of Education and Physical Training of the Czech Republic entitled "The management of agricultural and river landscape in the Czech Republic, with a special focus on the development of biodiversity", and research project MSM 6215648902 "Forest and wood support of functionally integrated forest management and the use of wood as a renewable raw material".

\section{REFERENCES}

Canter, L. (1995). Environmental Impact Assessment. 2nd ed. New York: McGraw-Hill Science, pp 480.

Esri, ArcGIS 9 (2002). Using ArcGIS 3D Analyst. 1st ed. Redlands, ESRI Press, pp 374. Fischer, P. (1996). Extending the applicability of viewsheds in landscape planning. Photogrammetric Engineering and Remote Sensing, 62: 1297-1302.

Hadrian, D.R., Bishop, I.D. \& Mitchel, Tree R. (1998). Automated mapping of Visual Impacts in Utility Corridors. Landscape and Urban Planning. 16: 2661-282.

Hanna, K.C. (2003). GIS for Landscape Architects. 2nd ed. Redlands: ESRI Press, pp 106.

Howes, D., Gatrell, T. (1993). Visibility analysis in GIS: Issues in the environmental impact assessment of windfarm developments. In: Hart, J., Ottens, H.F.L. \& Scholten, H.J. (Eds.), Proceedings of the 1993 European Conference on Geographical Informations Systems. pp 861-870. Utrecht: ESRI,

Jancura, P., Slamova, M. \& Trizuliakova, K. (2001). Panoramy. Enviromagazin: casopis o tvorbe a ochrane zivotneho prostredia. 6 (6): 18-19.

Kent, M. (1986). Visibility analysis of mining and waste tipping sites: A review. Landscape and Urban Planning, 27 (1): 101-110.

Klimanek, M. (2006). Digitalni modely terenu. Textbook, 1st ed. Brno, MZLU, pp 85.

Lipsky, Z., Romportl, D. (2006). Krajinne indikatory pro hodnoceni zmen krajinneho razu. In: Vorel, I., Sklenicka, P.: Ochrana krajinneho razu: trinact let zkusenosti, uspechu $i$ omylu. 51-56 p. Sbornik prispevku z conference.

Leita, O B.A. (1997). Landscape Capacity Evaluation and Visual Impacts Simulation a GIS Approach. Proceedings of the 12th ESRI European User Conference, 29.9.-1.10.1997. Copenhagen: ESRI.

Miller, D., Morrice, J., Horne, P. \& Aspinall, R. (1994). Characterisation of landscape views. In: Hart, J., Ottens, H.F.L. \& Scholten, H.J. (Eds.), Proceedings of the 1994 European Conference on Geographical Informations Systems / MARI. pp 223-232. Utrecht: ESRI,

Mills, K., Fox, G. \& Heimbach, R. (1992). Implementation and visual exposure analysis model on a parallel computing system. Computers and geosciences, 18: 766-771.

Mitchell, A. (1999). The ESRI Guide to GIS Analysis: Geographic Patterns and Relationships. 1st ed. Redlands: Environmental Systems Research Institute, inc., pp 186.

Möller, B. (2007). Could Landscape Intervisibility be a Suitable Criterion for Location of Wind Turbines? In: Wachowicz, M., Bodum, L. (Eds.), 10th AGILE International 
Conference on Geographic Information Science 2007. 1-7 pp. 1st edition. Aalborg: Aalborg University.

O'sullivan, D., Turner, A. (2001). Visibility graphs and landscape visibility analysis. International Journal of Geographical Information Science, 15: 221-237.

Ramos, B., Panagopoulos, T. (2004). The Use of GIS in Visual Landscape Management and Visual Impact Assessment of a Quarry in Portugal. Proceedings of the 8th International Conference on Environment and Mineral Processing. Vol I. 1st edition. Ostrava: 24-26 June: 73-78.

Rana, S., Morley, J. (2002). Optimising visibility analyses using topographic features on the terrain. CASA Working Papers Series, 44: 1-29.

Salasova, A., Kuchynkova, H., Kaslova, J., Seibert, R., Stancl, L. \& Rimmel, V. (2008). Studie moznosti umisteni vetrnych elektraren na uzemi ORP Bruntal. Ostrava: Regionalni centrum EIA.

Salasova, A., Kuchynkova, H., Lacina, D., Psotova, H., Lorenzova, P. \& Krek, P. (2007). Preventivni posouzeni krajinneho razu CHKO Beskydy. Otrokovice: Arvita P.

The Landscape Institute and Institute of Environmental Management and Assessment (2002). Guidelines for Landscape and Visual Impact Assessment. 2nd ed. London - New York: Spon Press, pp 166.

Vorel, I., Bukacek, R., Matejka, P., Culek, M. \& Sklenicka, P. (2006). Metodicky postup: Posouzeni vlivu navrhovane stavby, cinnosti nebo zmeny vyuziti uzemi na krajinny raz. 1st ed., Praha: pp 23. 